\title{
EVOLUTION OF GESTALT PRINCIPLES IN CONTEMPORARY GRAPHIC DESIGN
}

\author{
Jonas Malinauskas \\ Vilnius College of Technologies and Design, Design faculty, Vilnius, Lithuania \\ Member of LGDA - Lithuanian Graphic Design Association
}

\begin{abstract}
From the very beginning of XX century the principles of Gestalt helped humans to simplify and structure their visual surrounding. Despite aesthetic evolutions, it always helped to keep the clarity and readability of visual messages. Alas, development of global digital communications simulated the appearance of many stereotypes, clichés and templates, which has led to a loss of quality and originality, total convergence of visual language.

Today, when marketing - orientated designers replaces visual artists creating posters and prints, attention and reconsideration of visual information, encoded in their graphics, gets a growing importance. Knowingly made visual errors, inaccuracies can not only attract the attention, but also encourage the viewers to rethink them. On the other side, ingeniously disintegrated parts of the composition or some "visual riddles" provokes the viewer to turn his intelligence on; as a result, the whole of the visual message acquires a much greater value than it's separate parts.

The mentioned development of digital technologies also offers unlimited image transformation capabilities, and also encourages wider use of dynamic compositions, based on video formats. Quick visible changes or movements (from chaos to structure etc.) helps to attract and keep viewer's attention.

The study of changes in Gestalt principles most of all concerns prints and poster as a universal genre of graphic design that combines individual artistic expression with adaptive graphic communication. The research of exchanges is based on analysis of examples of printed and digital Gestalt applications.
\end{abstract}

Key words: Gestalt, rules of gestaltung

"Design is the conscious effort to empose a meaningful order" Victor Papanek

\section{DEFINITION AND SHORT HISTORY OF THE OBJECT}

Gestalt (unified whole - germ.) -- unity of form, image, structure of some physical object or virtual model. Only few terms in the field of print and design have German origin, noting the contributions of scientists of this country in research of this area. Above all, it concerns the studies, made just before the First World War in Frankfurt Psychological Institute by young scientists Wolfgang Köhler, Max Wertheimer, and Kurt Koffka (Figure 1). Their researches were based on the ideas of Max Planck and Carl Stumpf about the link between physics and psychology. The young scientists collaborated on the founding of a new holistic attitude toward psychology called Gestalt theory, aspects of which were grounded on the earlier work of C. Stumpf.

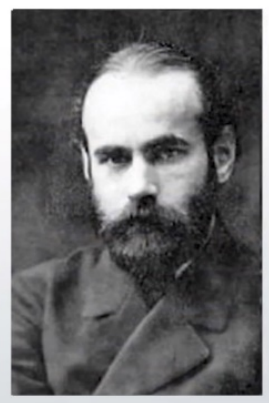

Max Wertheimer (1880-1943)

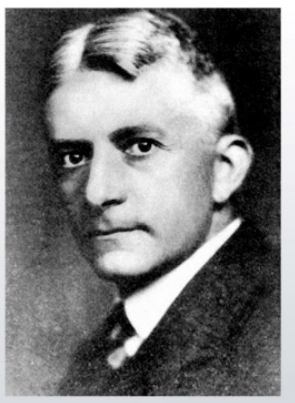

Wolfgang Kohler (1887-1967)

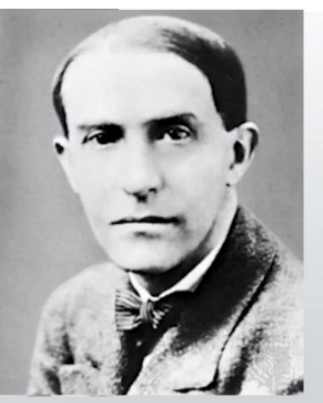

Kurt Koffka (1886-1941)

Figure 1: The researches of Gestalt theory 
Developing the studies of apparent movement, they came to conclusion of inherent nature of human vision. The essential sentence, describing the Gestalt phenomena, was "The whole is different from the sum of its parts" (Lupton et al, 2015) which due to possible translation mistake, sounds as "the whole is greater than the sum of its parts". Most of specialists, including psychologists and communication theorists, today explain it as to mean that the relationship links (physical and logical) between the parts is itself a significant part and gives an additional value to the whole, which is not present in the other parts if simply summed up. The classical example of this thesis is the parts of the car, which being disassembled and laying on the floor do not mean the car as an object - they need to be assembled in specific sequence and order (Figure 2).

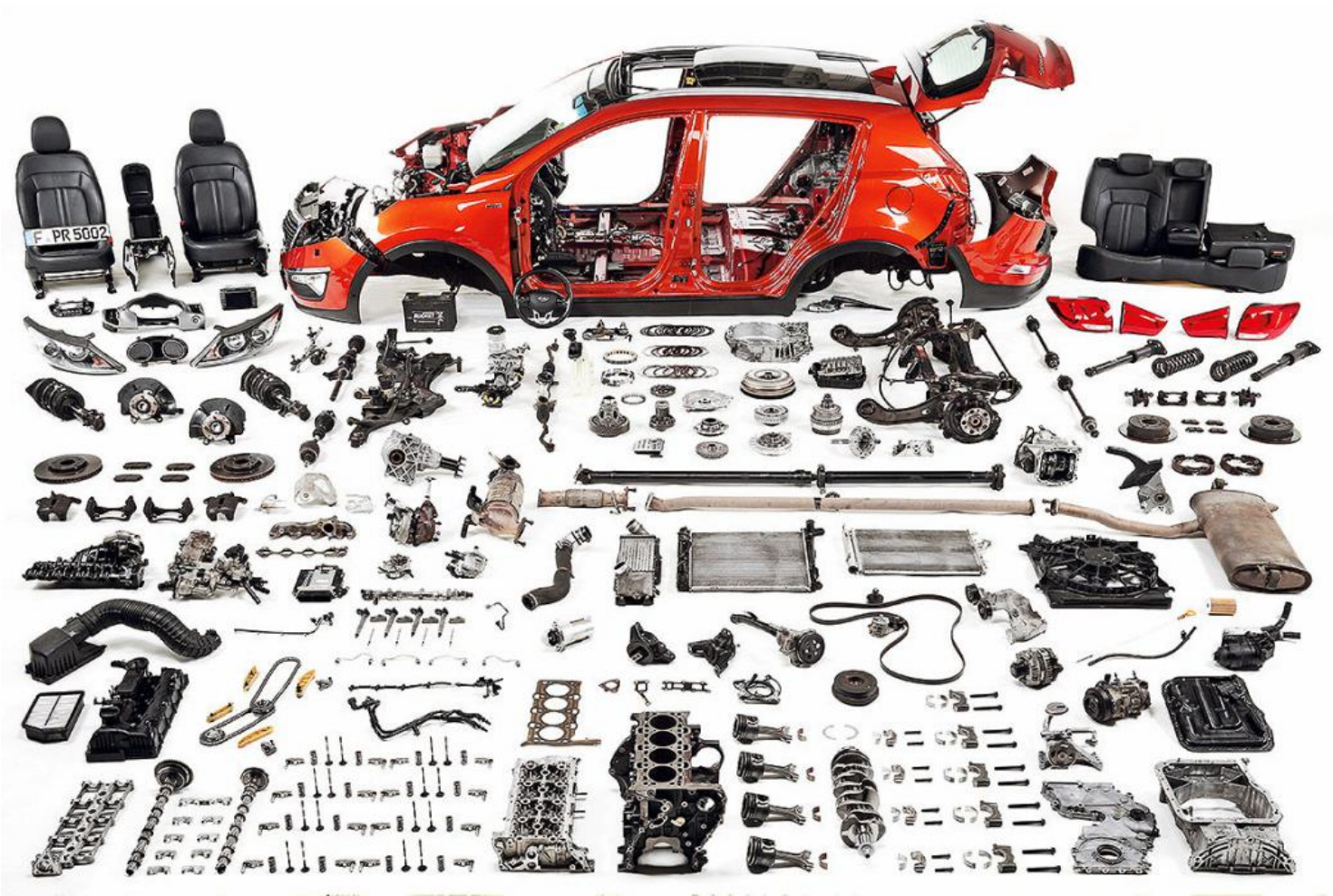

Figure 2: The whole gestalt objects, as an assembled car, have greater value, than the sum of its parts.

Finished gestalts are always integrities, and show overall integrity of human consciousness, which is a complete structure, consisting of members belonging to the whole, more or less distinct from each other. Speaking about psychology, interhuman relations and communication, outside the formed visual ot virtual structure there are additional gestalt-qualities with deeper emotional content. Today, examinating any kind of art we have to understand a gestalt like as a whole, integrating informational and emotional features of its parts and reaching a new level of expression. Gestalt models are created at the highest level of human consciousness. It is necessary to mention that this phenomena, first described during psychology studies, now is also used in a wide context of interpersonal relations and human behavior. The aim of both Gestalt applications in psychology and visual arts is finding some common features and insertion of structural order in chaotic, noisy atmosphere of human surrounding.

\section{2. "CLASSICAL" METHODS OF GESTALTUNG}

The aim of contemporary theory, created on the base of the German scientist's researches is to explain, how complex scenes can be reduced to more simple shapes. It also explains the ways, which people unconsciously use to connect and link design elements. There are 6 acknowledged basic principles of visual perception (Figure 3). 


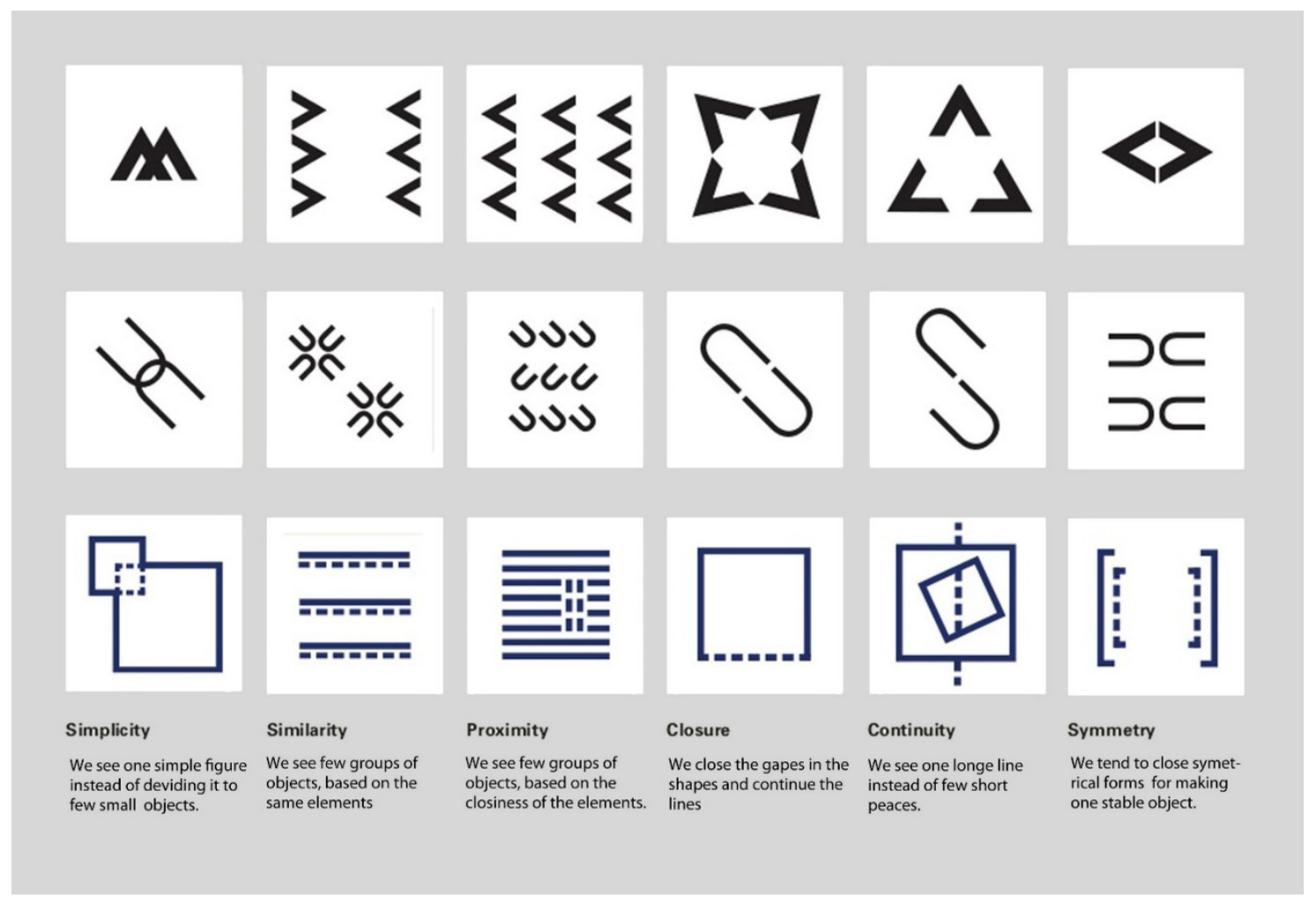

Figure 3: The basic principles of visual perception.

- Figure/Ground (or Simplicity): The human eye tries to isolate shapes from backgrounds and to describe the figures as simple and integrated as possible.

- Similarity. The human eye tends to build a relationship between similar elements within a design, building some kind of structure. Similarity can be achieved concentrating attention to basic composition elements such as shapes, colors, and size.

- Proximity: Simple shapes arranged together can create a more complex image

- Closure: We prefer to see complete shapes, which are easy to understand. If the visual elements are not complete, we can perceive a complete shape by unconscious using of imagination and filling in missing visual information (Figure 4)

- Continuity: The human eye follows the paths and lines of a design, and prefers to see a continuous flow of visual elements rather than separated objects. The effectiveness of this method depends on intermediate brakes or additional graphic elements.

- Symmetry and balance: The design should be balanced and complete; otherwise, the user will spend time and effort trying to perceive an overall picture.

Since the formulation of the "classic" gestalt principles, few decades passed by, and the amount of visual information, received every day has increased many times. Today, the methods of image recognition processes help to understand how a human mind transforms a huge stream of visual information into a meaningful and integrated image of the surrounding world. They also help to optimize ways of processing information, effectively exploiting the possibilities of human senses and consciousness.

On the other hand, information flow-makers are very interested in targeting and memorizing their messages, and therefore deliberately go beyond the established limits of information perception rules in order to attract users' attention and make them notice the incoming information. 


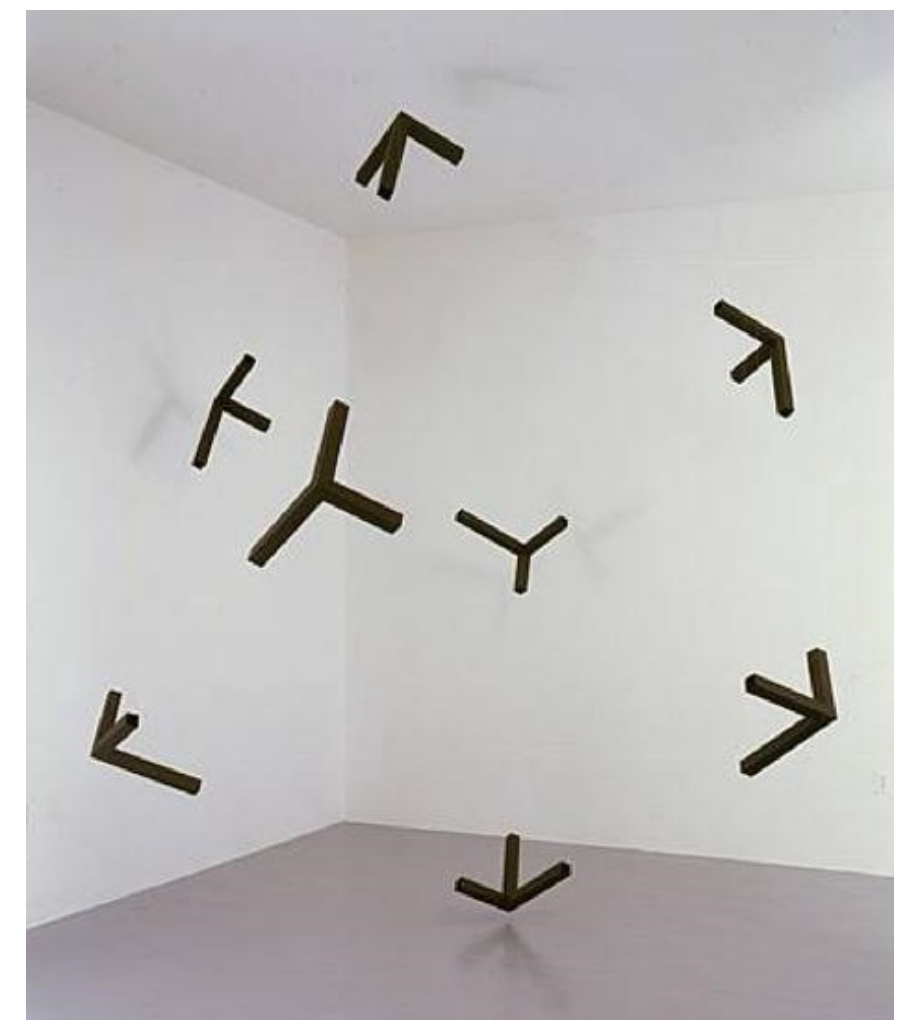

Figure 4: Uncomplete model of cube demands some spatial imagination

\section{CORRECTIONS AND TRANSFORMATIONS}

Realizing the potential for applying Gestalt thinking helps artists and designers create really eye-catching works. They've got new insights and ways of approaching problems and challenges, which cause radical changes in the graphic design.

As a rule, new tendencies appear in the form of individual phenomena or singular artistic works. However, if fashion motifs or social movements stand for them, they soon turn into new means of expression in graphic design. Sometimes they get traits of uncomplicated gestalt, causing "visual irritation". Among the innovations related to changes in gestalt methods, the following factors could be noted:

- $\quad$ Reverse of figure/ground contrast. Sometimes the figure or some intensive eye-catching elements become a frame or a background for flat inactive foreground. This reverse usually is dedicated to create some visual misunderstanding or to convey secondary meaning (Figures 5 and 6 )

- Color similarity, destroying text structure. Color can unify the pieces of printed or written text, displayed in unusual way or having large gaps, so being almost unreadable. If reader spend more time reading the text - he'll better understand and remember it in spite of poor readability. The play of the colors also brings some decorative effect (Figures 7 and 8)

- Proximity of symbolic figures. The small figures, forming one large gestalt object or brand logo, can have some narrative or symbolic meaning, communicating brand value and enriching the content (Figure 9)

- $\quad$ Simplicity and symbolic meaning. The simple shapes, containing symbolic meaning, have their roots in visual communication and religious iconography. The visual quests always attracts watcher's attention. (Figure 10) 

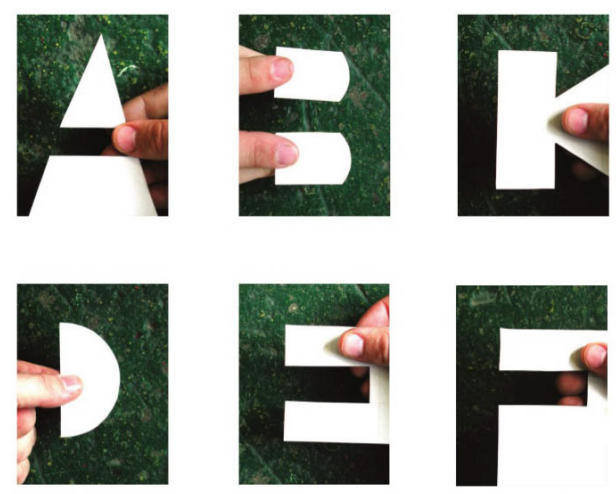

Figure 5: Making background from foreground Des. FWIS

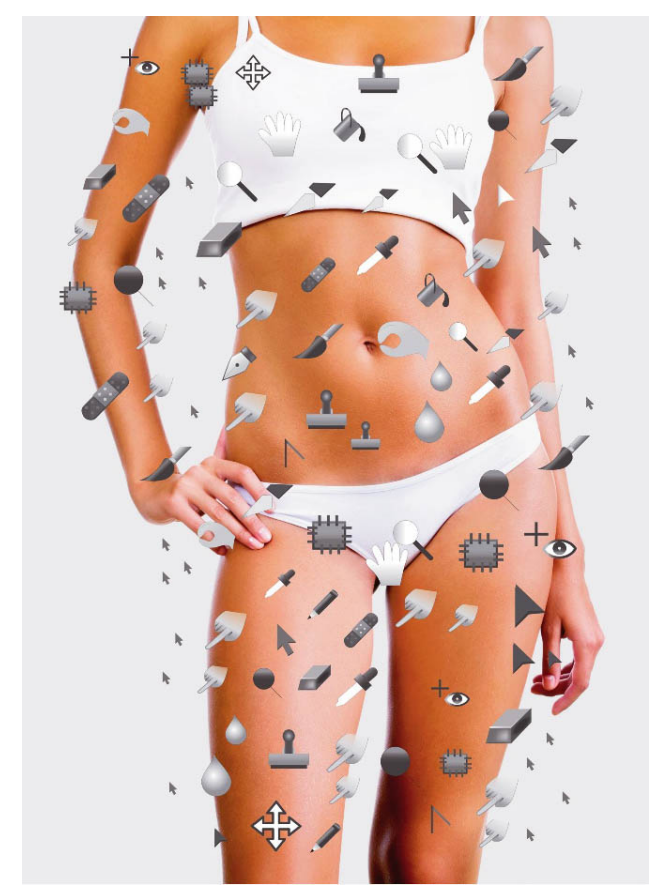

Figure 6: The human body as a background for secondary elements. Des. Shiva Nallaperumal,MFA (USA)

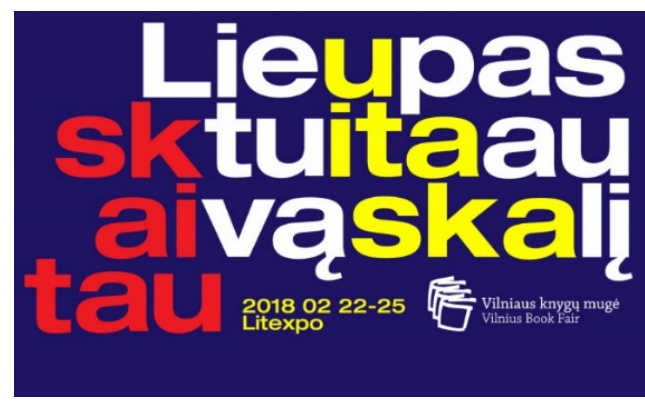

Figure 8: Book fair poster, des. Laura and Indre Klimate (Lithuania)

\section{STUDIO} i 1 [

(Germany)

\section{REAL BURGRAZI 99423 Weima}

Figure 7: Art exhibition poster, des. Felix Wetzel

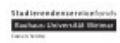

MIT 25.01. 20.0 SCHWING

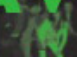

\section{KÜNSTLER}

MZYK

TER P P $\mathbf{P}$ L L E R ŽMIIEWSKI

12.12. 20.00

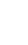




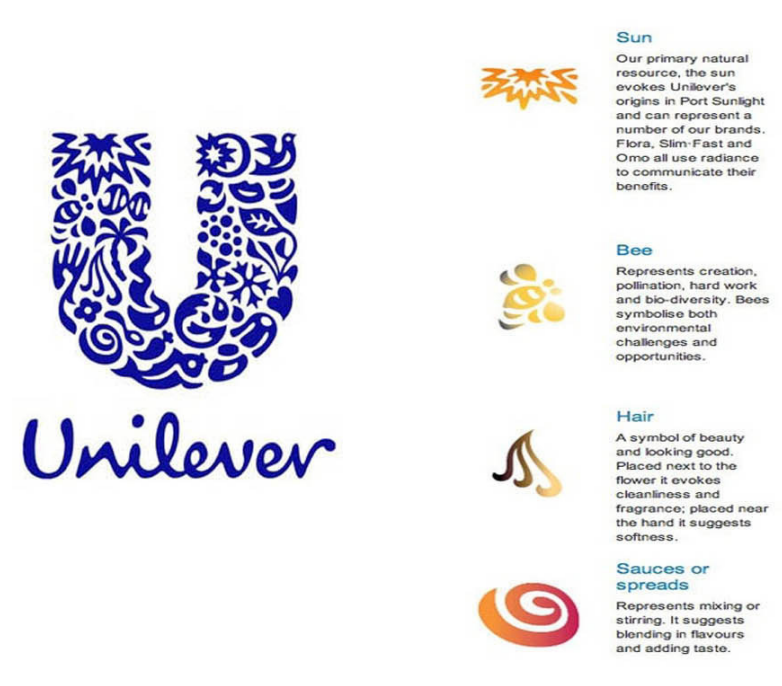

Figure 9: Unilever company logo (USA)

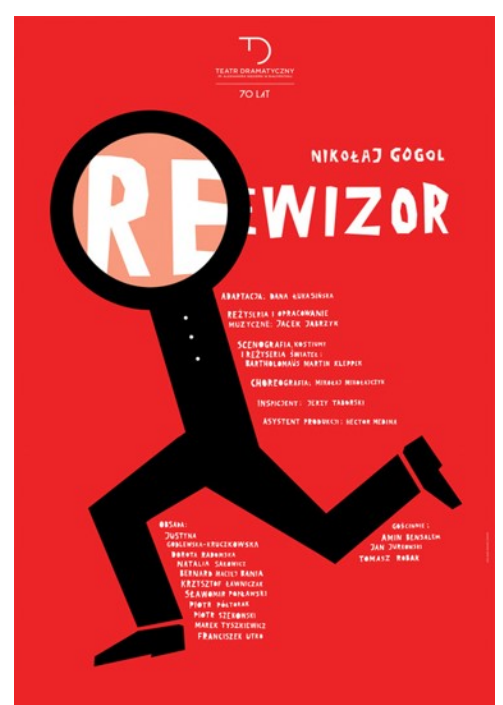

Figure 10: Theatre poster, des. Agnieszka Popek- Banach (Poland)

\section{UNFINISHED GESTALT IN SOCIAL CONTEXT}

Unfinished gestalt in Graphic design can mean some imperfection, causing positive or negative sequences. Extrapolating this feature to the field of personal psychological well-being means some disappointment and negative emotions. The features of unfinished gestalt in interpersonal/social communication are:

A. The search for important aims in life, giving negative results.

B. Permanent delays in the execution of important and less important tasks; constant delay

C. The termination of interpersonal relations with unfixed or indefinite results and unexplained reasons.

D. Leaving some activity or work unfinished in in-between stage.

E. Feeling some strange irritation and discomfort inside, thinking about these occurrences.

Applying these circumstances to creative activity, we will receive the signs of internal psychological disturbance, inhibiting and disorganizing the creative process:

A. Continuing feeling of chronic displeasure or anxiety inside our body and mind.

B. Temporary feeling of self-guilty and disappointment in personal creative abilities

C. On deeper level - there appears essential obstacles in achieving the essential professional goals.

D. Demand of effective social or creative activities from other persons; trying to implement the unrealized creative ambitions on younger generation (this feature is especially important for teachers)

„Personality always seeks to complete unfinished gestalt and to achieve a sense of integrity and harmony. When certain life events and situations, as well as feelings and experiences associated with them, come to a logical conclusion, a person comes to a state of calm and confidence, which is felt not only on an emotional, but also on a bodily level" (Kohler, 2015)

The recommended way for getting out of this situation is sorting of the gestalts according to the intended scope and starting of execution from simple tasks that can be standardized. This process can be compared to medical abscess cut, initially giving physical pain, followed by relief and healing. Even a partial implementation of the volume will ease the burden of psychological pressure.

It is important to know that pursuit of simple alternative physical activities does not provide relief in solving creative problems 


\section{CONLUSIONS}

- The principles of gestalt still are the basic principles of visual perception, helping the consumers to avoid visual overflow and to form an integrated vision of surrounding world.

- These principles, connected to psychology of perception, used to be flexibly adopted to contemporary aesthetic context.

- Transferring the principles of gestalt to the field of interpersonal relations can cause psychological problems and negative feelings in case of unfinished process.

\section{REFERENCES}

[1] Kohler, W.: "The Task of Gestalt Psychology", (Princeton Legacy Library, New Jersey, 2015.)

[2] Lupton, E., Philips, J.C.: "Graphic design. The New Basics", 2nd ed., (Princeton Architectural Press, New York, 2015.)

(c) (1)

(c) 2018 Authors. Published by the University of Novi Sad, Faculty of Technical Sciences, Department of Graphic Engineering and Design. This article is an open access article distributed under the terms and conditions of the Creative Commons Attribution license 3.0 Serbia (http://creativecommons.org/licenses/by/3.0/rs/). 